\title{
Noise Exposure and Noise Induced Hearing Loss Among the Traffic Police in Dhaka Metropolitan City
}

\author{
Naha $\mathrm{A}^{1}$, Akhtar $\mathrm{N}$, Datta $\mathrm{PG}^{3}$, Rahman $\mathrm{MH}^{2}$, Majumder $\mathrm{RA}^{4}$, Haque $\mathrm{MH}^{2}$, Biswas $\mathrm{AK}^{2}$, \\ Mahmud $\mathrm{MK}^{5}$ \\ ${ }^{1}$ Sheikh Fazilatunnessa Mujib Memorial KPJ Specialized Hospital \& Nursing College, Gazipur, \\ Bangladesh; ${ }^{3}$ Green Life Hospital, Dhaka, Bangladesh; ${ }^{2}$ Bangabandhu Sheikh Mujib Medical \\ University, Dhaka, Bangladesh; ${ }^{4}$ Mugda General Hospital, Dhaka, Bangladesh; ${ }^{5}$ National Institute of \\ Cancer Research \& Hospital, Dhaka, Bangladesh
}

\begin{abstract}
Background: Occupational noise is considered as a global problem with social and physiological impacts, causing noise-induced hearing loss (NIHL). High levels of occupational noise is a problem in all regions of the world. Road traffic produces high noise levels that can cause damage to the traffic police hearing. Hence, occupational hearing loss is a well-known outcome of noise exposure at work.

Objectives: The study aimed to measure the noise exposure level at different traffic points and determine the occurrence rate and severity of hearing loss among the traffic police of Dhaka Metropolitan City.

Methods: This cross-sectional study was conducted during 2017-2019 in 28 selected traffic points of Dhaka Metropolitan City under four traffic zone (East, West, North, and South) and among 100 traffic police who were working there and met the inclusion and exclusion criteria. Noise exposure level was measured from all selected traffic points with a digital sound level meter. Data were collected by face to face interview with a pretested semi-structured questionnaire followed by an otoscopic examination, tuning fork tests, and a baseline audiogram. To see the association, Chi-square tests or Pearson's correlation coefficient (r) tests were performed.

Results: This study revealed that the average noise exposure level at East, West, North, and South zones are respectively $125.6 \mathrm{~dB}, 112.9 \mathrm{~dB}, 121.3 \mathrm{~dB}$, and $119.4 \mathrm{~dB}$. At every point, the noise exposure level was more than the acceptable limit set by the Occupational Safety and Health Administration (OSHA). In the audiometry report of 100 traffic police, $64 \%$ had sensorineural hearing loss. Of them $85 \%$ had mild, $9 \%$ had moderate and $6 \%$ with severe hearing loss. Notch in $4 \mathrm{kHz}$ in an audiogram was present in the right ear of $46 \%$ of respondents and left ear of $52 \%$ respondents. It was observed that hearing loss was significantly associated with increasing age and job duration.
\end{abstract}

Conclusion: Traffic police of Dhaka Metropolitan City is in constant risk of noise induced hearing loss as the ambient noise of this city is very high. Regular assessment and hearing screening is recommended for all the traffic police who are exposed to noise.

Keywords: Noise exposure, Noise-induced hearing loss, Traffic police, Audiogram

\section{Introduction}

Every human activity is associated with some form of noise. When assessing its impact on social well-being, it is usually classified as occupational noise, which is environmental noise, including noise in the community, residential or domestic level like traffic, playgrounds, sports, music, or sound in the workplace. ${ }^{1}$

Globally rapid urbanisation, industrialisation, and a developed transportation system are the essential reasons behind this increased noise levels. ${ }^{2}$

${ }^{*}$ Correspondence: Abirvab Naha, ENT-Specialist, Sheikh Fazilatunnessa Mujib Memorial KPJ Specialized Hospital \& Nursing College, Gazipur, Bangladesh; email:dr.abirvab@gmail.com; ORCID:0000-0002-7034-1797
The World Health Organization (WHO) currently estimates disabling hearing impairment presents among 432 million adults in the world, two-thirds of these people from developing countries and half of deafness and hearing impairment is avoidable. ${ }^{3}$ According to the WHO, in adults, $16 \%$ of disabling hearing loss is due to occupational noise exposure. ${ }^{4}$ Excessive exposure to occupational noise results in well-recognised occupational hearing loss, and it is taken as a global problem.

Noise-induced hearing loss (NIHL) is the most common cause of sensorineural hearing loss after presbyacusis (age-related hearing loss). ${ }^{5}$ Repeated 
and sustained exposure to excessive sound level causes NIHL. It is a sensorineural type of hearing loss and usually bilateral, irreversible, and progressive. ${ }^{6}$ It is a preventable and predictable disease with an epidemiologically relevant prevalence in urban communities. The presence of a sensorineural hearing loss in the audiogram, mostly pronounced in the high-frequency region between $3,000 \mathrm{~Hz}$ to $6,000 \mathrm{~Hz}$ with the most significant hearing loss, is specifically around the 4,000-Hz area (i.e., 4,000 Hz dip) is identical. ${ }^{7}$

The Occupational Safety and Health Association (OSHA) sets $90 \mathrm{dBA}$ as the time-weighted average (TWA) for an 8-hour workday exposure to noise. ${ }^{8}$ According to the National Institute of Occupational Safety and Health (NIOSH), this limit is 85 dBA. $^{9}$

In the city, the average traffic sound is about $60-100$ $\mathrm{dB} .{ }^{10}$ When there is exposure to sound level approximately $85 \mathrm{~dB}$, initially, it causes temporary dullness of hearing (temporary threshold shift), which usually recovers within 24 hours of exposure. Still, if there is repeated sustained exposure, the threshold shift becomes permanent (permanent threshold shift) due to nerve fiber degeneration. ${ }^{11,12}$

NIHL is one of the most common problems among the traffic police. Most of them are aware of the air pollution, but most of them remain unaware of the long-term ill effect of noise on their hearing ability because this is an insidious process and takes a long time to become overt. ${ }^{13,10,14}$ On humans, exposure to traffic noise has several acute and chronic effects. $^{7,15}$ It may cause insomnia, annoyance, hearing loss, mental disorders, and adverse physiological and psychological impacts. ${ }^{13}$ It may also increase the activity of endocrine glands, affects heart rates, produce high blood pressure, and cause changes in blood composition. ${ }^{16}$

One study in Dhaka Metropolitan city was carried out among 100 traffic police officers from January 2003 to June 2004, where they measured the noise level at different traffic points of Dhaka city and the traffic police's hearing status. They found that $24 \%$ of the respondent having mild to moderate NIHL. ${ }^{17}$

Many studies have been conducted to observe the noise effect in industrial workers, but little attention has been paid to noise caused by automobiles and their impact on traffic police. With this background present study was carried out to evaluate traffic noise exposure levels of traffic police personnel serving at busy points of Dhaka metropolitan city and to assess whether they suffer from NIHL.

\section{Materials and Method}

This study was designed as a cross-sectional study. It was conducted in the Department of Otolaryngology and Head-Neck surgery at Bangabandhu Sheikh Mujib Medical University for clinical assessment and 28 different traffic points of Dhaka Metropolitan City to measure sound level during March 2017 to July 2019. Traffic police of Dhaka metropolitan city who has worked for more than five years in the traffic division, aged 26 to 45 . Traffic police presented with a systemic disease like hypertension, diabetes mellitus, collagen disease, history of viral disease, drug therapy which may cause SNHL, duration of service less than five years and previous history of otitis media and known causes of conductive or sensorineural hearing loss were excluded from this study. A total of twenty-eight different points were selected randomly, seven points from each traffic zone under Dhaka metropolitan City. First Measurement of environmental sound intensity level in twenty-eight selected traffic points were done by using a digital sound level meter (REED SD - Model SD-4023). Sound levels were measured three times a day once at every point i.e., from $0700-0900$ hours in the morning, $1600-1800$ hours in the evening, and $2000-2200$ hours at night and 10 minutes per reading at each point. Measurements were taken at the location where traffic personnel was stationed, to determine the noise levels they are exposed to. Sound level measurement data from the SD-4023, was analysed using the environmental software $\mathrm{CD}$ version SW-U801-WIN provided by REED SD. Then exposure of average noise level or TWA was calculated from Lden, using the formula introduced by OSHA. Data were collected through face to face interviews of each respondent. After examining the ear, an otoscopic examination of the tympanic membrane and tuning fork test of each respondent was done. Finally, PTA and tympanometry tests were carried out by clinical audiometer (Grason Stadler 61) Calibrated with a frequency range of $125 \mathrm{~Hz}$ to $8000 \mathrm{~Hz}$ and sound intensity levels of between $-10 \mathrm{~dB}$ to $120 \mathrm{~dB}$ was used to test each ear of the subject separately. Audiometric testing of the subjects was conducted at least 8 hours after the last noise exposure to exclude a temporary threshold shift. Hearing losses were categorized according to the WHO guidelines based on the findings. The data were calculated in an excel spreadsheet then exported SPSS (22.0) for analysis. The statistical significance 
was set to $p<0.05$. A Chi-Square test was done to compare the categorical variables. Pearson's correlation coefficient (r) test was performed to explore the relationship of the hearing threshold at 4 $\mathrm{kHz}$ with age and duration of noise exposure of traffic police in Dhaka metropolitan city.

\section{Results}

In this cross-sectional study, traffic police were selected from twenty-eight different points of four traffic zones of Dhaka metropolitan city after taking proper permission from Dhaka Metropolitan Police Headquarter, Bangladesh. Then the average noise level of those twenty-eight traffic points was calculated by using a noise level calculator. A total sample of 100 traffic police from twenty-eight different traffic points of Dhaka city with a $100 \%$ response rate was taken for hearing assessment.

In the East Traffic zone, the highest sound level measured 129.6 dB at DIT road, Rampura, and lowest at Bangshal that measured $43.7 \mathrm{~dB}$. Noise exposure or TWA maximum at DIT Road Rampura, and it was $132.8 \mathrm{~dB}$. The lowest TWA was found at the AGB colony; it was $107 \mathrm{~dB}$ (figure 1).

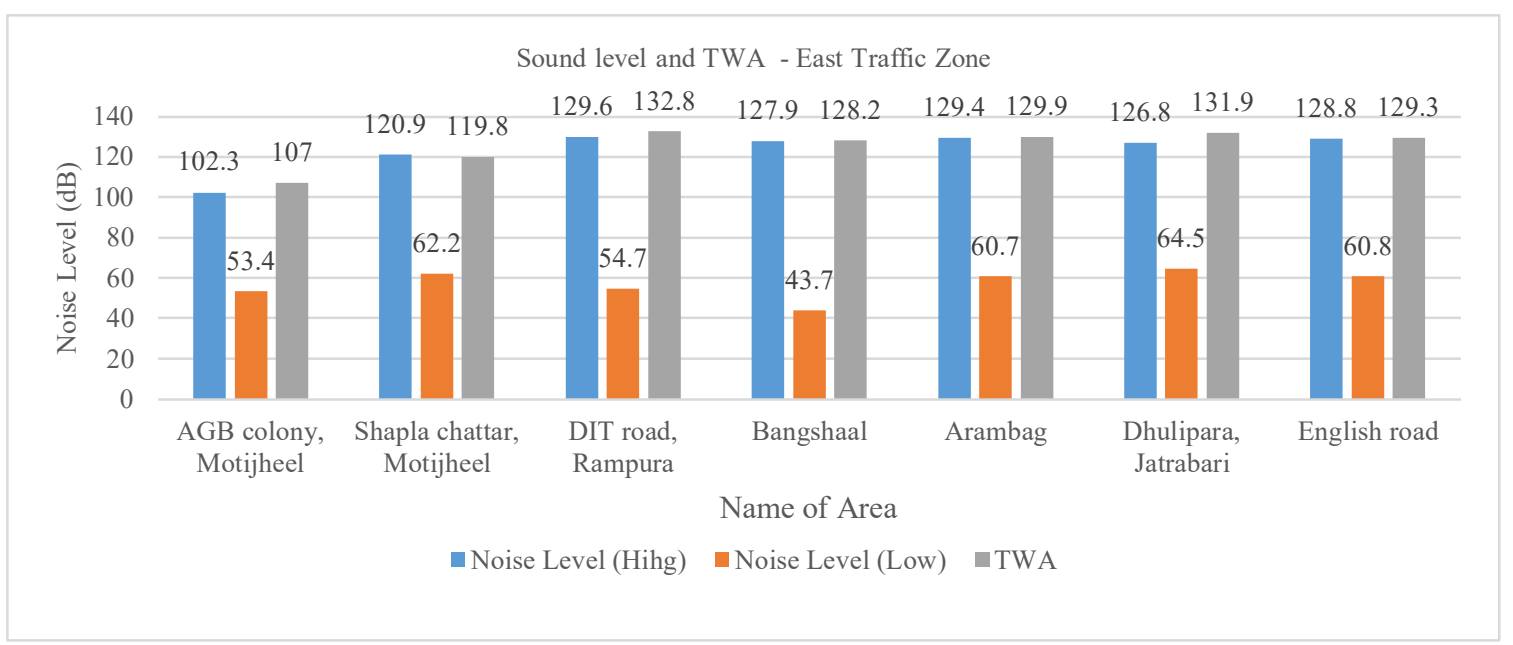

Figure 1: Bar chart showing highest and lowest sound level with TWA in seven points of East zone.

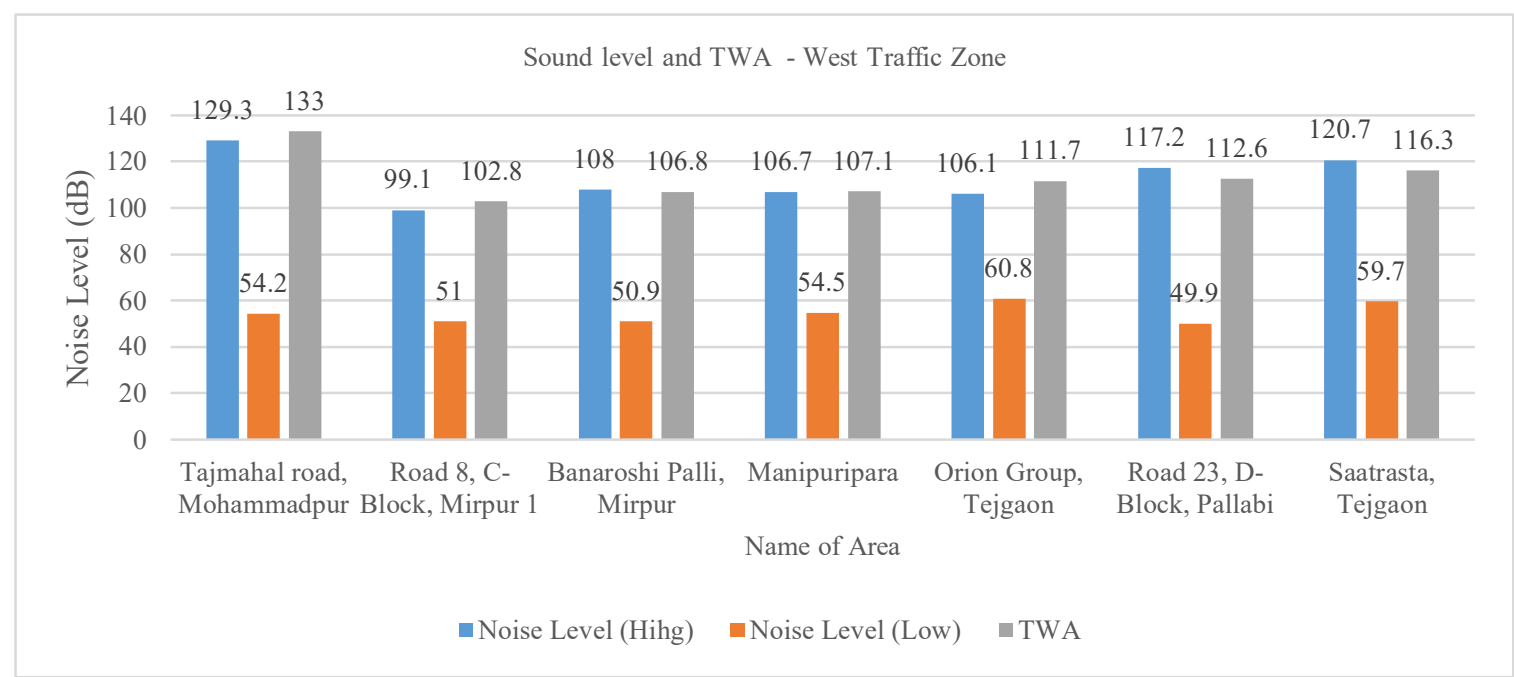

Figure 2: Bar chart showing highest and lowest sound level with TWA in seven points of West zone.

In the West Traffic zone, the highest sound level measured $129.3 \mathrm{~dB}$ at Tajmahal Road, Mohammadpur, and lowest $49.9 \mathrm{~dB}$ at Road 23, D-Block, Pallabi. Noise exposure or TWA highest at 
Tajmahal Road, Mohammadpur, and it was 133.0dB. Lowest TWA found at Road 8, C-Block, Mirpur 1 ; it was $102.8 \mathrm{~dB}$ (figure 2).

Nikunja in the North traffic zone where both highest and lowest sound levels were recorded was 129.6 $\mathrm{dB}$ and $44.9 \mathrm{~dB}$. The highest TWA was recorded $129.5 \mathrm{~dB}$ at ICDDRB, Mohakhali, and the lowest TWA at Road 101, Gulshan 1, which was $110.3 \mathrm{~dB}$ (figure 3).

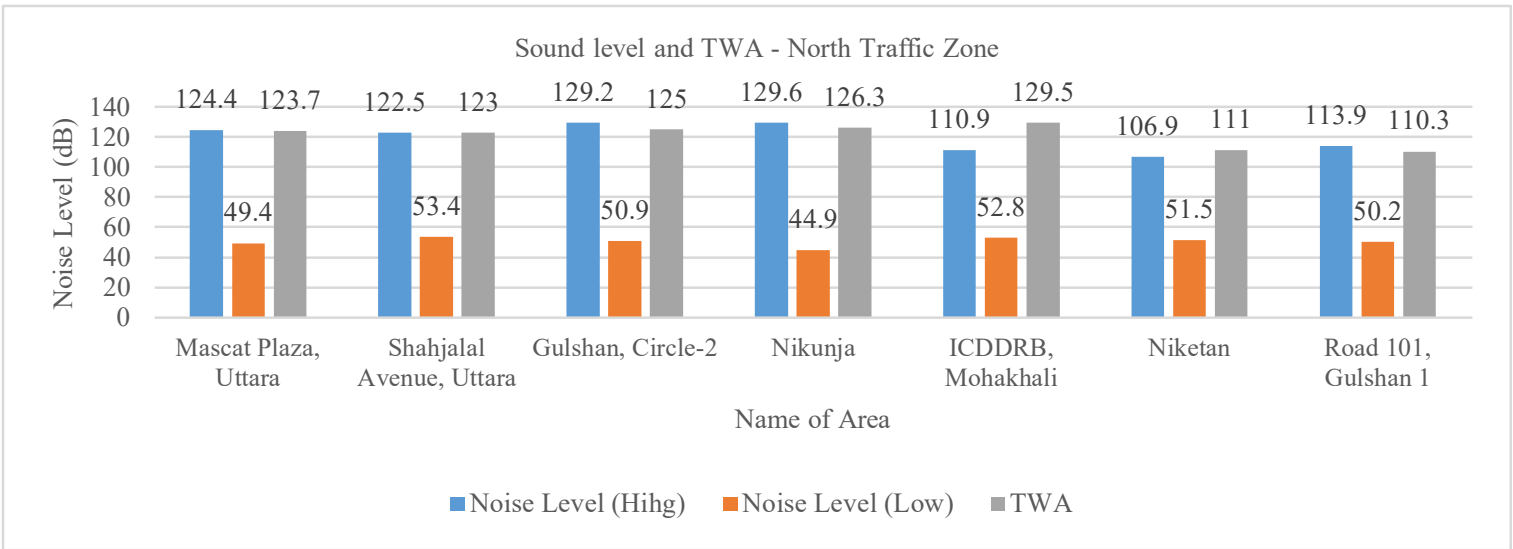

Figure 3: Bar chart showing highest and lowest sound level with TWA in seven points of North zone.

From seven different points under the South traffic zone, we got the highest sound level of $129.5 \mathrm{~dB}$ at Road 5, Dhanmondi, and lowest $43.7 \mathrm{~dB}$ at R S Street, Lalbag. The highest and lowest TWA were found at the Bata signal, Elephant Road, and Eskaton respectively $132.0 \mathrm{~dB}$ and $108.7 \mathrm{~dB}$ (figure 4).

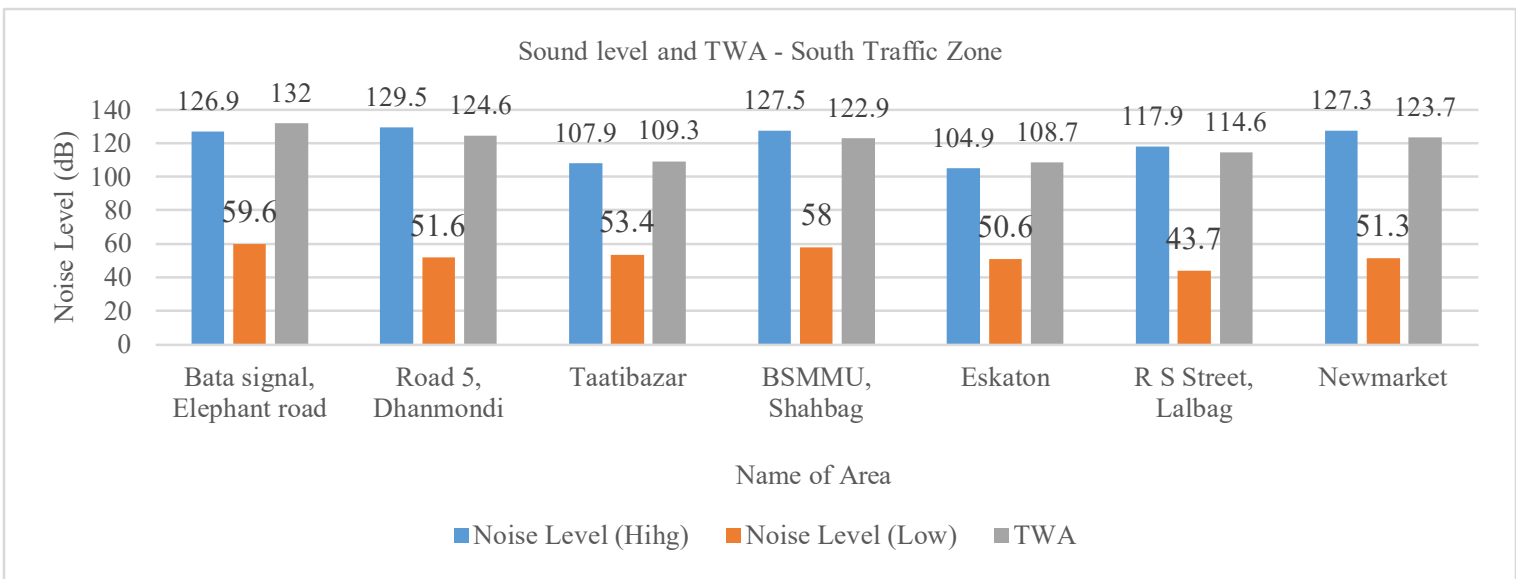

Figure 4: Bar chart showing highest and lowest sound level with TWA in seven points of South zone.

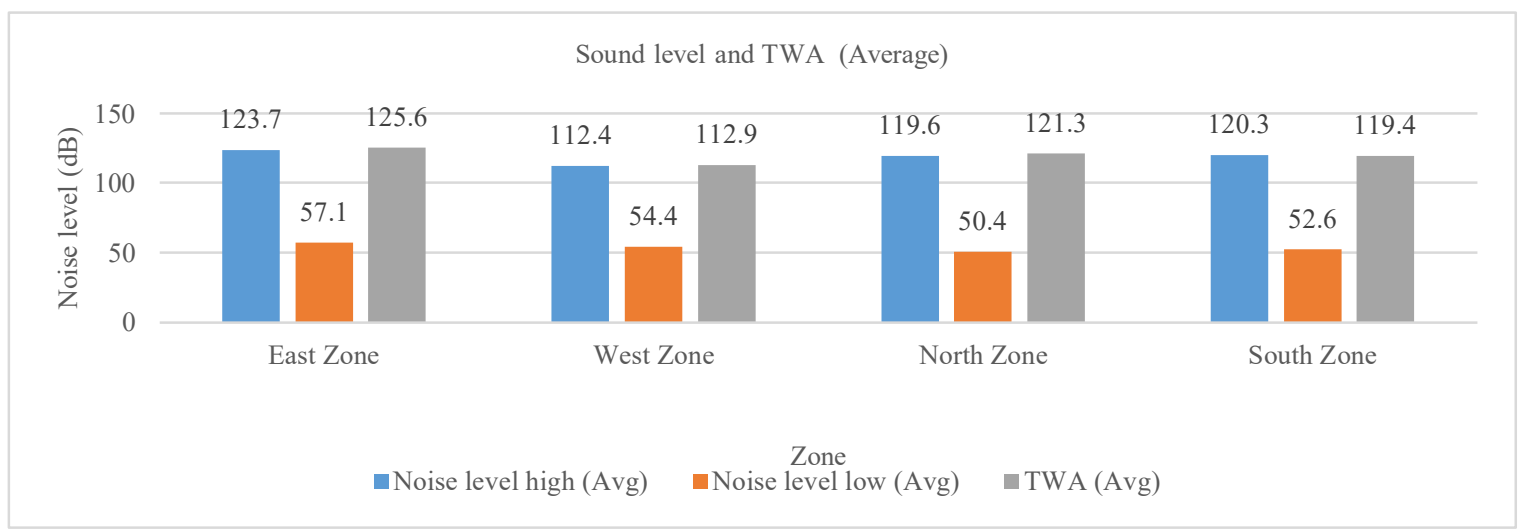

Figure 5: Bar chart showing highest and lowest sound level with TWA of four traffic zones. 
After measuring sound levels at different traffic points of all four zones, we made an average sound level and TWA of them. Among four zones, we got the highest sound level $123.7 \mathrm{~dB}$ at East zone and lowest sound level $50.4 \mathrm{~dB}$ in the North zone. Regarding TWA, we found the highest $125.6 \mathrm{~dB}$ in the East zone. The lowest TWA was calculated $112.9 \mathrm{~dB}$ in the west zone. TWA of North and South zone was respectively $121.3 \mathrm{~dB}$ and 119.4 $\mathrm{dB}$ (figure 5).

In this study, the age distribution was noted with a maximum of $44.0 \%$ subjects from $41-45$ years, followed by $24.0 \%$ in the age range of $36-40$ years. The mean age was $38.9 \pm 5.2$ years, and the range was from 28 to 45 years. Here, gender distribution was noted with $100.0 \%$ male, and duty time for all respondents was 8 hours/day.

Maximum $32 \%$ of respondents were present in both 16-20 years and 21-25 years of job duration group. $24.0 \%$ from $6-10$ years group and the lowest $12.0 \%$ from $11-15$ years group. The mean duration of the job was $16.9 \pm 6.5$ years, and rage was 5-25 years (table I).

Hearing assessment of all 100 traffic policeman was done, and results revealed that $64.0 \%$ had hearing impairment, and $36.0 \%$ had normal hearing.
Table I: Distribution of the respondents on the basis of job duration $(\mathrm{n}=100)$

\begin{tabular}{lll}
\hline $\begin{array}{l}\text { Duration of job } \\
\text { (in years) }\end{array}$ & Frequency & $\begin{array}{l}\text { Percentage } \\
\text { (\%) }\end{array}$ \\
\hline $6-10$ & 24 & 24.0 \\
$11-15$ & 12 & 12.0 \\
$16-20$ & 32 & 32.0 \\
$21-25$ & 32 & 32.0 \\
Total & 100 & 100.0 \\
Mean \pm SD & $16.96 \pm 6.54$ & \\
Range & $(5-25)$ years & \\
\hline
\end{tabular}

Among those hearing-impaired traffic police highest $85.0 \%$ of respondents had a mild degree of hearing loss, $9.0 \%$ had a moderate degree, and $6.0 \%$ had a severe degree of hearing loss. We did not find any respondents with profound hearing loss.

The data represents that $81.2 \%$ of respondents got hearing impairment who have been working for 1620 years. In the $21-25$ years group, $75.0 \%$ got hearing loss, which is the second-highest figure. The lowest $33.3 \%$ hearing loss was found in 6-10 years group. $50.0 \%$ of respondents from the group 11-15 years has got some hearing loss. It also shows that there is an association of hearing loss with a job duration of respondents (table II).

Based on pure tone audiometry, when specific 4 $\mathrm{KHz}$ frequency was considered ( $>25 \mathrm{db}$ ), $46.0 \%$ of respondents had hearing loss in the right ear, and $52.0 \%$ had hearing loss in the left ear, where $34.0 \%$ had a notch at $4 \mathrm{KHz}$ in both ears.

Table II: Association between hearing loss and job duration of the respondents $(n=100)$

\begin{tabular}{|c|c|c|c|c|c|c|c|c|}
\hline \multirow{2}{*}{\multicolumn{2}{|c|}{$\begin{array}{c}\text { Duration of service } \\
\text { (years) } \\
\text { n }\end{array}$}} & \multicolumn{6}{|c|}{ Hearing status - No. (\%) } & \multirow[t]{2}{*}{$p$-value } \\
\hline & & \multirow{2}{*}{\begin{tabular}{|c|} 
0-25 dB \\
Normal \\
$16(66.7 \%)$
\end{tabular}} & \multirow{2}{*}{$\begin{array}{l}\begin{array}{l}26-40 \mathrm{~dB} \\
\text { Mild HL }\end{array} \\
6(25.0 \%)\end{array}$} & \multirow{2}{*}{$\begin{array}{c}\begin{array}{c}\text { 41-60 dB } \\
\text { Moderate } \\
\text { HL }\end{array} \\
2(8.3 \%)\end{array}$} & \multirow{2}{*}{$\begin{array}{c}\begin{array}{c}61-80 \mathrm{~dB} \\
\text { Severe HL }\end{array} \\
0(0.0 \%)\end{array}$} & \multirow{2}{*}{$\begin{array}{c}>81 \text { dB } \\
\begin{array}{c}\text { Profound } \\
\text { HL }\end{array} \\
0(0.0 \%)\end{array}$} & \multirow{2}{*}{$\begin{array}{c}\begin{array}{c}\text { Total } \\
\text { HL }\end{array} \\
8(33.3 \%)\end{array}$} & \\
\hline $6-10$ & 24 & & & & & & & \multirow{5}{*}{$0.002 *$} \\
\hline $11-15$ & 12 & $6(50.0 \%)$ & $4(33.3 \%)$ & $0(0.0 \%)$ & $2(16.7 \%)$ & $0(0.0 \%)$ & $6(50 \%)$ & \\
\hline $16-20$ & 32 & $6(18.8 \%)$ & $22(68.8 \%)$ & $2(6.3 \%)$ & $2(6.3 \%)$ & $0(0.0 \%)$ & $26(81.2 \%)$ & \\
\hline $21-25$ & 32 & $8(25.0 \%)$ & $22(68.8 \%)$ & $2(6.3 \%)$ & $0(0.0 \%)$ & $0(0.0 \%)$ & $24(75 \%)$ & \\
\hline Total & 100 & $36(36.0 \%)$ & $54(54.0 \%)$ & $6(6.0 \%)$ & $4(4.0 \%)$ & $0(0.0 \%)$ & $64(64 \%)$ & \\
\hline
\end{tabular}

Scatter diagram showed the degree of hearing loss in audiogram at $4 \mathrm{kHz}$ level increased with the increase in job duration (figure 6).

In this study highest TWA found $125.6 \mathrm{~dB}$ in East traffic zone, and $72 \%$ of respondents of that zone had hearing loss, which was also maximum in all zone. The lowest TWA was $112.9 \mathrm{~dB}$, which was in the West traffic zone, and $56.0 \%$ of respondents from that zone had hearing loss, which was also the lowest compared to other zones. The percentage of hearing loss from the North and South traffic zone was the same, and it was $64.0 \%$ where the TWA respectively $121.3 \mathrm{~dB}$ and $119.4 \mathrm{~dB}$. 


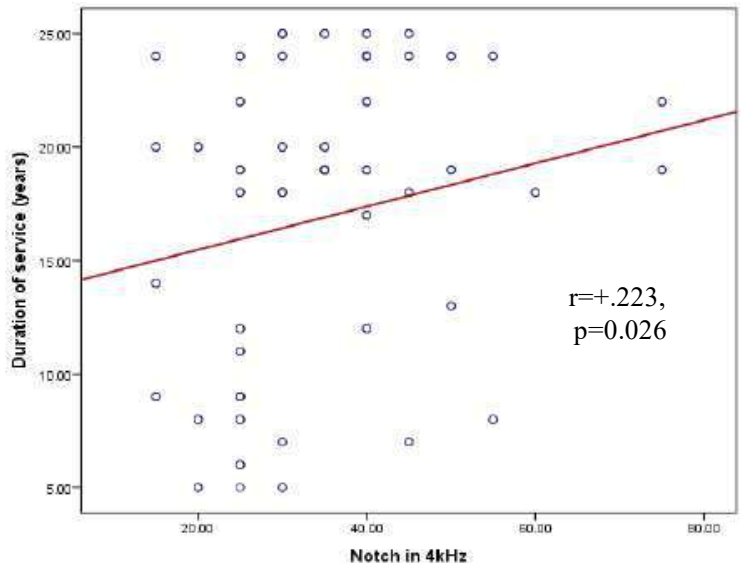

Figure 6: Scatter diagram showing the correlation of notch in audiogram at $4 \mathrm{kHz}$ with job duration of respondents (years)

\section{Discussion}

Most of the people in this country are not aware of their occupational health and occupational safety. Noise is one of the important out products in most of the occupational sector, and workers are not concerned about this noise pollution due to lack of knowledge. Road traffic is a significant source of noise in the urban area of Bangladesh, and high exposure to the noise causes NIHL, which is sensorineural in type.

In east traffic zone among seven traffic points, the noise level ranging from $43.7 \mathrm{~dB}$ to $129.6 \mathrm{~dB}$ and TWA ranging from $107.0 \mathrm{~dB}$ to $132.8 \mathrm{~dB}$. The highest sound level was measured at DIT road, Rampura 129.6 dB, and lowest at Bangshal $43.7 \mathrm{~dB}$ and TWA was highest $132.8 \mathrm{~dB}$ at DIT road, Rampura and lowest 107.0 dB at AGB colony, Motijheel, where the highest and lowest sound level was respectively $102.3 \mathrm{~dB}$ and $53.4 \mathrm{~dB}$. A similar study was conducted in Dhaka city, where they observed the highest sound level at Motijheel $90 \mathrm{~dB}$ and lowest $84 \mathrm{~dB} \cdot{ }^{17}$

In west traffic zone sound level ranging from $129.3 \mathrm{~dB}$ to $49.9 \mathrm{~dB}$ where highest $129.3 \mathrm{~dB}$ at Tajmahal road, Mohammadpur and lowest $49.9 \mathrm{~dB}$ at Road-23, D-Block, Pallabi. Maximum TWA $133.0 \mathrm{~dB}$ at Tajmahal Road, Mohammadpur, and minimum TWA $102.8 \mathrm{~dB}$ at Road-8, C-Block, Mirpur, where the highest sound level was 99.1 $\mathrm{dB}$, and lowest was recorded $51 \mathrm{~dB}$. According to the previous similar study conducted in Dhaka, they found sound level highest $95 \mathrm{~dB}$ and lowest $90 \mathrm{~dB}$ at Mirpur $1 .{ }^{17}$

Among seven points from North traffic zone highest and lowest sound levels were found at Nikunja, which was $129.6 \mathrm{~dB}$ to $44.9 \mathrm{~dB}$. The highest TWA was recorded $129.5 \mathrm{~dB}$ at ICDDRB,
Mohakhali, and the lowest TWA at Road 101, Gulshan 1, which was $110.3 \mathrm{~dB}$. The average noise level was recorded $88.6 \mathrm{~dB}$ at the Gulshan area in a similar study, which was much lower than this study. ${ }^{17}$

In the south traffic zone, it was measured the highest sound level of $129.5 \mathrm{~dB}$ at Road 5, Dhanmondi, and lowest $43.7 \mathrm{~dB}$ at R S Street, Lalbag. The highest and lowest TWA were found respectively at the Bata signal, Elephant Road, and Eskaton that was $132.0 \mathrm{~dB}$ and $108.7 \mathrm{~dB}$. In this zone, it was to be found a sound level ranging from $127.3 \mathrm{~dB}$ to 51.3 $\mathrm{dB}$ at New-market and $126.9 \mathrm{~dB}$ to $59.6 \mathrm{~dB}$ at Elephant road traffic point. In a similar study, they found a sound level $76 \mathrm{~dB}$ to $80 \mathrm{~dB}$ at New-market and $88 \mathrm{~dB}$ to $94 \mathrm{~dB}$ at Elephant road. ${ }^{17}$

At Kuala Lumpur city of Malaysia, the traffic noise level was between $75 \mathrm{dBA}$ to $85 \mathrm{dBA}$. Occasionally, it was found $90 \mathrm{dBA}$ and rarely 100 dBA. ${ }^{18}$ Another study conducted at Jalgaon, India, revealed noise level ranges at different points of the city from $79.9 \mathrm{~dB}$ to $95.4 \mathrm{~dB}$, and TWA ranged from $102.0 \mathrm{~dB}$ to $124.4 \mathrm{~dB} .^{13}$

The present study showed a significant increase in noise level compared with the research done before. Increased vehicles, indiscriminate use of horns, massive mass movement, and lack of knowledge about traffic law may be the cause in our city. Similar noise was found in the study conducted at Jalgaon, India, but in Kuala Lumpur city noise level was lower than this study, which may be due to proper regulation of traffic law. ${ }^{13,18}$

On average highest sound level, $123.7 \mathrm{~dB}$ at East zone, and the lowest sound level of $50.4 \mathrm{~dB}$, was measured in the North zone. The highest TWA $125.6 \mathrm{~dB}$ was found in the east zone, and the lowest TWA was calculated $112.9 \mathrm{~dB}$ in the west zone. TWA of north and south zone was $121.3 \mathrm{~dB}$ and $119.4 \mathrm{~dB}$, respectively. The permissible noise level $90 \mathrm{dBA}$ for 8 hours working day exposure that had been set by OSHA. ${ }^{8}$ In this study, the noise level and noise exposure (TWA) were higher in every zone compared to the permissible noise level exposure stated by OSHA.

In this study, all respondents were male. The average age of the participant was $38.95 \pm 5.19$ years. Highest $44.0 \%$ of subjects in the age range of $41-45$ years, followed by $24.0 \%$ in the age range of 36-40 years. In the age range 31-35 years, we found $23.0 \%$ of respondents and $9.0 \%$ from $26-30$ years of the age range. A similar study conducted in Jammu, India among 150 traffic police where $56.7 \%$ of the subjects were in the age group of 
30 to 39 years, while minimum $8.0 \%$ of subjects were in the age group of $>50$ years, with a mean age of the study being $36.6 \pm 6.6$ years and a range from 25 to 56 years. ${ }^{19}$

Maximum $32.0 \%$ of respondents had job duration ranging from 16-20 and 21-25 years. The mean exposure duration was $16.9 \pm 6.5$ years. From the group of $16-20$ years highest, $81.8 \%$ had hearing loss. $75.0 \%$ of respondents had a mild to moderate degree of hearing loss from the group of 21-25 years of noise exposure. In a similar study conducted in Dhaka city, traffic police with a 6-10 year exposure group got $45.8 \%$ hearing loss, which was the highest, and $29 \%$ had hearing loss from the 16-20 years exposure group. From the 1115 years group, only $25.0 \%$ had hearing loss. ${ }^{17}$ Another study showed the highest $50.5 \%$ traffic police of the Royal Brunei Police Force had NIHL working for more than 15 years. ${ }^{20}$ The percentage of respondents with hearing loss was much lower compared to this study, and this might explain that the road traffic noise in Dhaka city increased very rapidly with the increased number of vehicles and created more effect in the hearing of traffic police. On the other hand, it showed the impact of repeated chronic noise exposure to high noise levels for a long duration. So, it proved a relation of NIHL with the length of the job, which is directly proportional.

It was to be found that $64.0 \%$ sensorineural hearing loss in this study. Among which, 85.0\% had a mild variety of hearing loss, $9.0 \%$ had a moderate type, and $6.0 \%$ had severe hearing loss. No one had a profound hearing loss. That was similar to the findings of other studies, where the prevalence of NIHL was found to be $24.0 \%$ in Dhaka city traffic police, $28.0 \%$ in French police officers, $66.4 \%$ in traffic police personnel in Kathmandu City, $81.2 \%$ in Pune traffic police in India, and $84.0 \%$ in traffic police in Jalgaon Urban Centre in India10. ${ }^{13,17,21,22}$ Demographic variation and higher traffic noise pollution in India and Kathmandu than in France cause the prevalence. Also, as a developed country, the awareness and use of hearing protective devices with adequate noise conservation programs lower the prevalence rate. On the other hand, the increased number of vehicles, old vehicles, misuse of horns, and lack of knowledge about noise pollution rapidly expand the prevalence of NIHL in Dhaka.

NIHL is predominantly bilateral, but it often occurs in only one ear and mostly at the $4 \mathrm{KHz} .{ }^{10}$ In this study, $46.0 \%$ had hearing loss in specific $4 \mathrm{kHz}$ frequency in Right ear and $52.0 \%$ in the left ear. In a study prevalence of asymmetrical hearing loss in $4.7 \%$, among 1461 patients with noise-induced hearing loss. ${ }^{23}$

In NIHL, hearing loss is caused by long-term, continuous exposure to noise. ${ }^{24}$ In this study, hearing loss in $4 \mathrm{kHz}$ positively correlated with the increase in job duration $(\mathrm{r}=+.223, \mathrm{I}=0.026)$. So, with the length of job long term, continuous exposure to noise occurred. That's why, in this study, hearing loss in $4 \mathrm{kHz}$ positively correlated with the job duration.

In this study, noise exposure (TWA) was a maximum $125.6 \mathrm{~dB}$ in East traffic zone, where $72.0 \%$ of respondents had hearing loss, which was maximum among four zones. The lowest noise exposure (TWA) was found at west traffic zone 112.6 , and $56.0 \%$ of respondents had hearing loss. So, here it was to be found high noise exposure causes more hearing loss.

In this study, noise level and noise exposure were higher than other studies as well as higher than the acceptable limits set by the Occupational Safety and Health Administration (OSHA). NIHL increased with an increase in a job duration, and it is similar to other studies. There was also a significant correlation of specific $4 \mathrm{kHz}$ hearing loss in audiogram with a job duration is identical in NIHL. Association of tinnitus, sleep disturbance, and annoyance with NIHL also noticeable from this study, which are common effects of NIHL. Moreover, we found that hearing loss among the respondents was higher when the noise level and sound exposure were high.

\section{Conclusion}

In Dhaka Metropolitan City, the noise level and noise exposure rate were very high at every traffic point. There was a strong direct association between NIHL with the duration of their job. It's also producing an adverse effect on their physical and mental wellbeing. This study concludes that traffic police working in Dhaka Metropolitan city are at very high risk for NIHL.

\section{Acknowledgement}

Authors acknowledge the support and cooperation of the teachers of the Department of Otolaryngology \& Head-Neck surgery, Bangabandhu Sheikh Mujib Medical University. Authors would also like to thank the Traffic Police Department of Dhaka Metropolitan City for their support and for being a part of this research. 
Conflict of interest: The authors declare that they have no conflict of interest.

Funding: Bangabandhu Sheikh Mujib Medical University (BSMMU) and self.

Ethical approval: IRB of BSMMU, Dhaka

Submitted: $24^{\text {th }}$ August, 2020

Final revision received: $15^{\text {th }}$ November 2020

Accepted: $25^{\text {th }}$ November 2020

Published: $1^{\text {st }}$ December, 2020

\section{References}

1. Concha-Barrientos M, Campbell-Lendrum D, Steenland K. Occupational Noise: Assessing the burden of disease from work-related hearing impairment at national and local levels. Environmental Burden of Disease Series: World Health Organization, Geneva, Switzerland. 2004; No 9.

2. Salehin S, Islam KMN, Alam MS, Hossain, MM. Industrial Noise Levels in Bangladesh: Is Worker Health at Risk?. Polish Journal of Environmental Studies. 2014; 23: 1719-26.

3. World Health Organization (WHO). Deafness and hearing loss, World Health Organization Factsheet. World Health Organization, Geneva, Switzerland. 2019;

URL:www.who.int/news-room/factsheets/detail/ deafness-and-hearing-loss.

4. Nelson DI, Nelson RY, Concha-Barrientos M, Fingerhut M. The global burden of occupational noise-induced hearing loss. American Journal of Industrial Medicine. 2005; 48: 448-58.

DOI: 10.1002/ajim.20223.

5. Taneja M. Noise-induced hearing loss. Indian Journal of Otology. 2014; 20: 151-4.

DOI: $10.4103 / 0971-7749.146928$.

6. Rodrigues H, Filho F, Ferraz D, Neto A, Torres S, Metidieri M. Noise-Induced Hearing Loss (NIHL): literature review with a focus on occupational medicine. International Archives of Otorhinolaryngology. 2014; 17: 208-12. DOI: 10.7162/S1809-97772013000200015.

7. Koh D, Jeyaratnam J. Occupational health in Singapore. International Archives of Occupational Environmental Health. 1998; 71: 295-301. DOI: $10.1007 / \mathrm{s} 004200050284$

8. Occupational Safety and Health Administration (OSHA) Laboratory safety noise. Occupational Safety and Health Administration Factsheet. United States Department of Labor, Washington, D.C., USA. 2009;

URL:www.osha.gov/Publications/laboratory/OS HAfactsheet-laboratory-safety-noise.html.
9. National Institute for Occupational Safety and health (NIOSH). National Institute for Occupational Safety and health Factsheet. U.S Department of Health and Human Service, Washington, D.C., USA. 2018;

URL:www.cdc.gov/niosh/topics/noise/default.html.

10. Shrestha I, Shrestha BL, Pokharel M, Amatya RCM, Karki DR. Prevalnace of Noise Induced Hearing Loss among Traffic Police Personnel of Kathmandu Metropolitan City. Kathmundu University Medical Journal. 2011; 9: 274-78. DOI: 10.3126/kumj.v9i4.6343

11. Dobie RA. Medical-legal evaluation of hearing loss. $3^{\text {rd }}$ edition, San Diego, Singular. 2001;393-95.

12. Thorne PR, Ameratunga SN, Stewart J, Reid N, Williams W, Purdy SC, Dodd G, Wallaart J. Epidemiology of noise-induced hearing loss in New Zealand. Journal of the New Zealand Medical Association. 2008; 121: 33-44.

13. Ingle ST, Pachpande BG, Wagh ND, Attarde SB. Noise exposure and hearing loss among the traffic policemen working at busy streets of Jalgaon urban centre. Transportation Research Journal. 2005; 10: 69-75.

DOI: $10.1080 / 15568310701398831$

14. Khan ST, Karadkhedkar S, Khadkekar S. Noise Induced Hearing Loss in City Traffic Policeman. Research and Reviews Journal of Medical and Health Science. 2014; 3: 26-28.

15. Uimonen S, Maki-Torkko E, Sorri M. Hearing and Occupation. International Journal Circumpolar Health. 1998; 57: 156-61.

16. Suter AH. Noise sources and effects - a new look. Sound and Vibration. 1992; 26: 18-38.

17. Sharif A, Taous A, Siddiquee, BH, Datta, PG. Prevalence of noise induced hearing loss among traffic police in Dhaka Metropolitan City. Mymensingh Medical Journal. 2009; 18: 24-28.

18. Thomas N, Mariah AN, Fuad A, Kuljit S, Philip R. Noise Exposure and Noise Induced Hearing Loss Among Kuala Lumpur Traffic Point Duty Personnel. Medical Journal Malaysia. 2007; 62: 152-5.

19. Sharma M, Dhar U, Kapoor M. A Study of Effect of Noise Exposure on the Hearing Level of Traffic Personnel. International Journal Oral Health Medical Research. 2015; 2: 19-22.

20. Win KN, Balalla NB, Lwin MZ, Lai A. NoiseInduced Hearing Loss in the Police Force. Safe Health Work. 2015; 6: 134-8.

DOI: $10.1016 /$ j.shaw.2015.01.002 
21. Lesage FX, Jovenin N, Deschamps F, Vincent S. Noise-induced hearing loss in French police officers. Occupational Medicine. 2009; 59: 483-486.

DOI: $10.1016 /$ j.shaw.2015.01.002

22. Singh VK, Mehta AK. Prevalence of occupational noise induced hearing loss amongst traffic police personnel. Indian Journal of Otolaryngology and Head \& Neck Surgery. 1999; 51: 23-26.

DOI: 10.1007/BF02997985
23. Chung DY, Willson GN, Gannon RP. Lateral differences in susceptibility to noise damage. Audiology. 1983; 22: 199-205.

24. Le TN, Straatman LV, Lea J, Westerberg B. Current insights in noise-induced hearing loss: a literature review of the underlying mechanism, pathophysiology, asymmetry, and management options. Journal of Otolaryngology - Head \& Neck Surgery. 2017; 46: 1-15.

DOI: $10.1186 / \mathrm{s} 40463-017-0219-\mathrm{x}$ 